\title{
Development of a 3D Grading Method for Shoe Lasts Based on Scanned 3D Foot Data
}

\author{
Jana SIEGMUND, Huangmei LIN, Sybille KRZYWINSKI, Monika RICHTER, Kathrin SCHÄFER \\ TU Dresden, Institute of Textile Machinery and High Performance Material Technology, Germany \\ Prüf- und Forschungsinstitut Pirmasens e. V., Pirmasens, Germany
}

https://doi.org/10.15221/19.119

\begin{abstract}
In the shoe manufacturing sector, products are typically designed for a small number of sample sizes, whereas all other shoe sizes in the range (for example, 2 to 4 shoe sizes below and above) are scaled using grading methods. However, the grading process significantly affects the fit and thus consumer acceptance. In this context, the shoe last forms the basis for all additional components to be used, such as insoles, midsoles, outsoles and heels. The entire shaft construction is based on the last as well. It also determines the fit of shoes. However, a method once established in the 1930s and still used today for the grading of shoe lasts is limited to only two dimensions, i.e. last length and technical ball circumference. The entire last is enlarged or reduced on the basis of these dimensions. The 3D CAD systems available today still employ the principle of mechanical last copying based on machines from the 1930s. Thus, the technical potential of these CAD systems is far from exhausted.

An innovative grading process allows shoe companies to better utilize and significantly expand the performance potential and technical capabilities of their 3D CAD systems. As the required amount of manual work in preparation for grading and last generation is considerably decreased, development times are shortened.
\end{abstract}

Keywords: 3D CAD, Foot scan, Shoe last, 3D grading method, Parametric design

\section{Introduction}

In the shoe industry, the construction of the shaft as well as all other components considerably depends on the last. When a new shoe product is manufactured, typically, only a small number of sample sizes is designed, whereas all other sizes in the range are scaled using grading methods. A method once established in the 1930s and still used today for the grading of shoe lasts is limited to only two dimensions, i.e. last length and technical ball circumference [1,2]. In order to generate length grading in the longitudinal direction, all last lengths are graded according to the shoe length increments within the corresponding sizing system. In contrast, for width grading, all width and circumference measurements of lasts are graded in accordance with the increments of width charts. In this context, "increment" refers to the difference between sample size and graded size, whereby length grading increments depend on the specific shoe size system. For example, the French stitch system involves a stitch length of $6.67 \mathrm{~mm}$, i.e. 1 stitch, from size to size, whereas the English system is based on $8.466 \mathrm{~mm}$ per stitch [3]. Last width and circumference measurements are graded based on the technical ball circumferences. Also, shoe size and width are assigned to technical ball circumferences in width charts. However, there are no generally recognized rules or standards in place so that many last manufacturers provide their customers with various width charts to choose from $[3,4]$. Hence, the last as a whole is enlarged or reduced based on these measurements.

However, a potential anatomical relationship between graded sizes and technical ball circumference has not been addressed so far. The sizes of heel as well as toe areas are graded according to the ball circumference. Since the gradation of these two sizes differs, distortions in shape and proportion occur. The required adjustments are time-consuming and typically based on experience rather than profound data or calculations. Investigations on the foot geometry of adults revealed that there is no proportional relationship between different foot areas and shoe size or foot length $[5,6]$. The grading technique used for lasts has never been adjusted to new technological developments or resulting new opportunities. In future, it is aimed at developing lasts based on foot-type-specific measurement charts. State-of-the-art 3D CAD solutions that are already successfully used in other industry sectors, offer a great potential in this regard.

Introducing 2D and $3 \mathrm{D}$ CAD systems to shoe and last manufacturers could not resolve the previously known insufficiencies of the standard grading technique. This was, for example, the case with "EasyLast" [7, 8]. This system enables the generation, modification, and grading of lasts based on digital last data; moreover, lasts can be manufactured using CNC machines. However, only two parameters can be included in the procedure: length and circumference. The inclusion of additional foot or last measurements is currently infeasible in spite of extensive research efforts $[9,10,11,12$, $13,14]$. 
Compared to the clothing industry, a sector that appears to be rather similar, there is an enormous difference in applied grading techniques and the state of the art. For example, there are detailed body measurement charts available in the clothing sector. Hence, the corresponding grading process is based on current body measurements and is consistently improved by means of extensive research efforts.

\section{General approach}

Our research project is aimed at the development and evaluation of innovative 3D grading methods suitable for lasts. In contrast to standard grading methods, this innovative process involves real measured foot dimensions. For each desired size and different foot types, a grading algorithm is provided, which contains all relevant information for last construction. In a next step, automated construction or $3 \mathrm{D}$ grading is performed based on measured data, corresponding waveforms of measurement paths, and determined spatial distances between foot and last. These grading procedures are highly efficient and significantly improve product fit according to latest research results provided by the clothing industry $[15,16,17,18,19,20,21,22,23,24,25,26,27]$.

\section{Development and scaling of middle foot models}

Several hundred foot data sets were extracted from a database (optical scan systems were used for recording) to develop standard foots from sizes 36 to 42 in three foot width types. In total, 210 data sets were processed, and "middle" foot models were generated by means of an ICP algorithm based on the data obtained from measurements in addition to selected sizes and foot types. Data sets were carefully chosen in terms of the quality of polygonal surfaces as not to invalidate the resulting middle foot models. The created polygonal models were modified according to requirements for virtual feet. To enable scaling, a corresponding scaling factor was calculated for each measurement path (Fig. 1, 2).

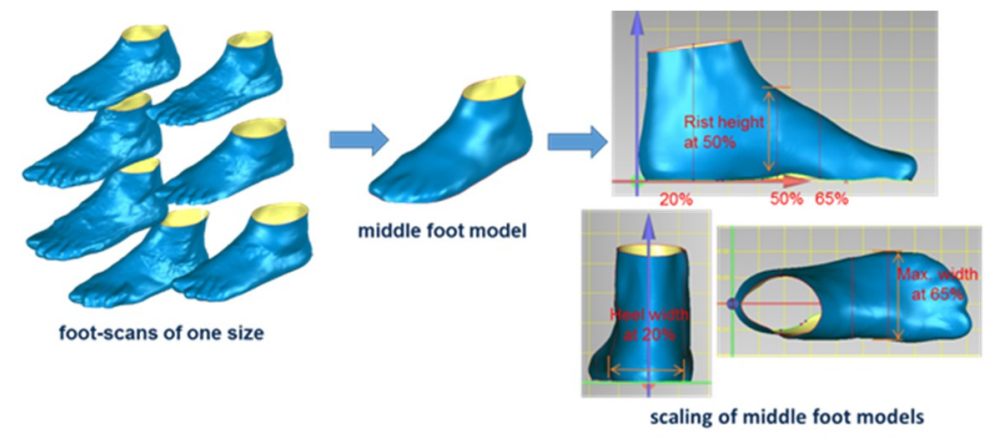

Fig.1: The generation process of middle foot models for sizes 36-42 and types I, II, III
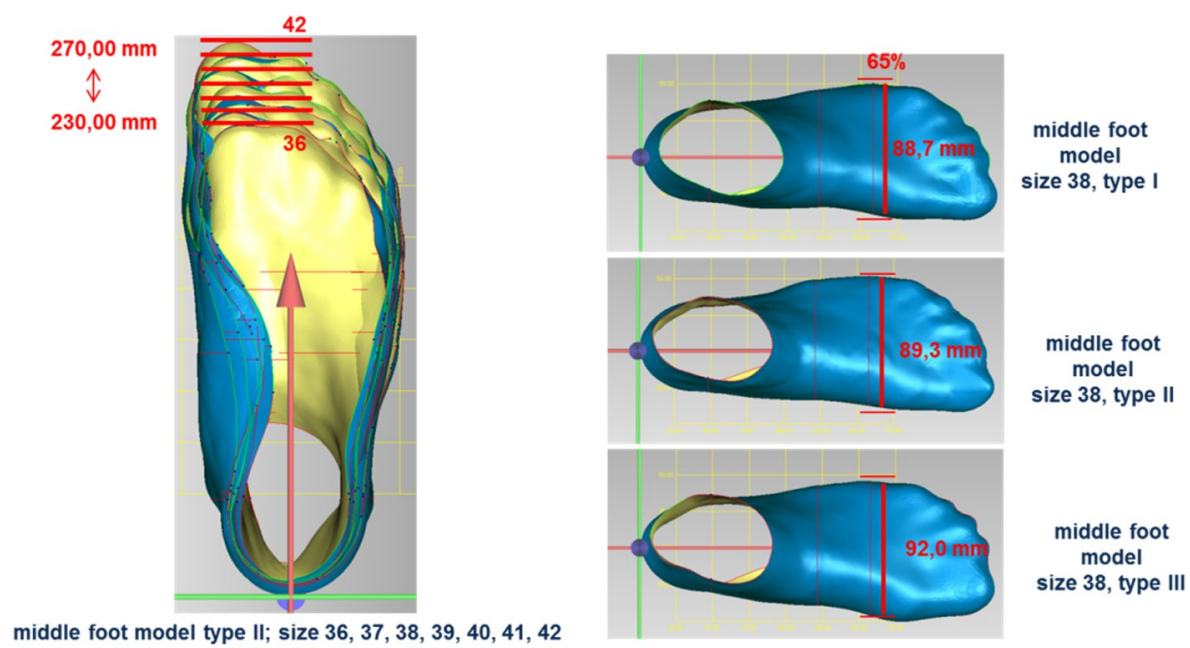

Fig. 2: Scaling of foot length and foot width according to the table

The resulting polygonal models in defined sizes and foot types provide the foundation for the further development of parametric foot models and the evaluation of computer-based foot grading. 


\section{Development of a grading method for middle foot models}

Based on these standard foots, a morphological grading method was derived. In order to achieve parametric foot models, the polygonal models of standard sizes are converted into spline models using reverse engineering, thus enabling further processing by a 3D CAD system. Characteristic foot curves [5] are positioned on the geometry data by means of the coordinates of measuring points, and the scaling directions, center points as well as additional scaling curves are established. The shape of the entire foot is determined by the crossing points of characteristic foot curves. The coordinates of the crossing points were measured and stored in Excel sheets for previously defined sizes and foot types. All individual points are connected via spline curves, thus generating the spline surface (Fig. 3).

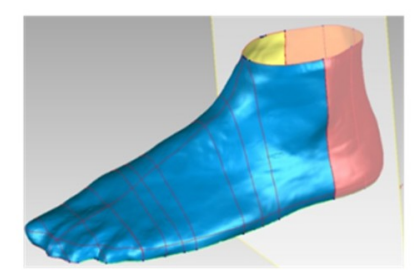

Middle foot model, polygon surface (Geomagic)

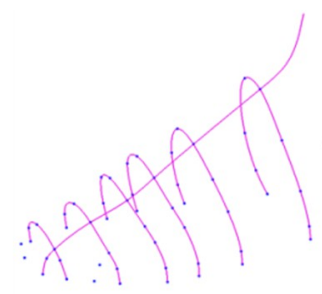

Construction of spline curves (DC3D, Lectra)
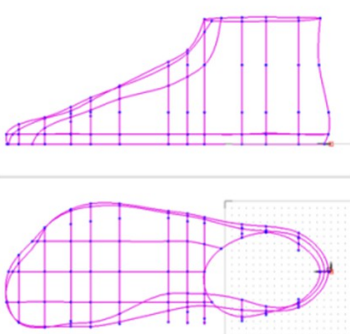

Coordinates of the crossing points as parameters $P_{i}=\left(x_{i}, y_{i}, z_{i}\right)$

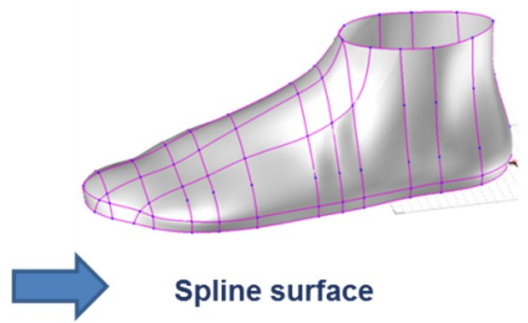

Fig. 3: Parametric middle 3D foot

The grading of 3D foot models is performed by parameterization. All sizes and foot types can be derived by exchanging parameters that are saved in Excel sheets (Fig. 4).
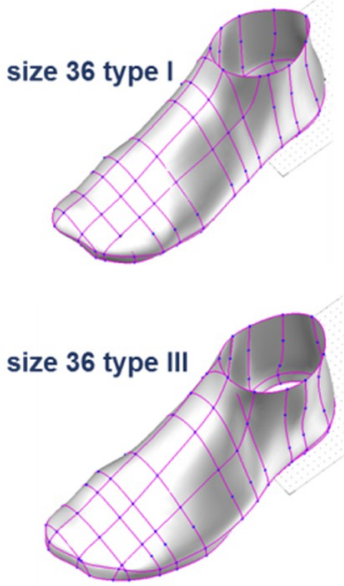

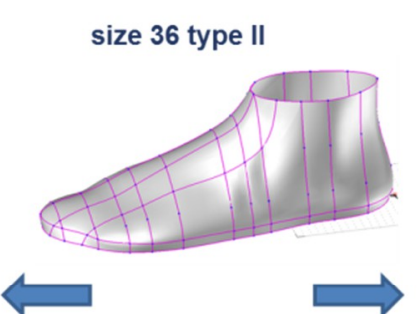

Parameter exchange

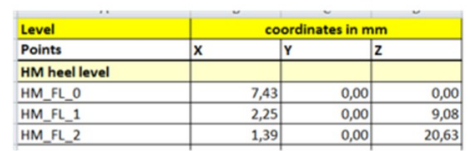

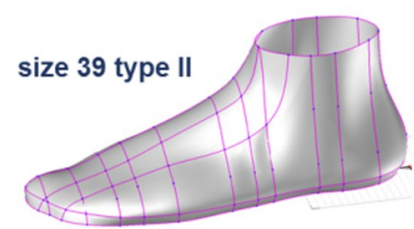

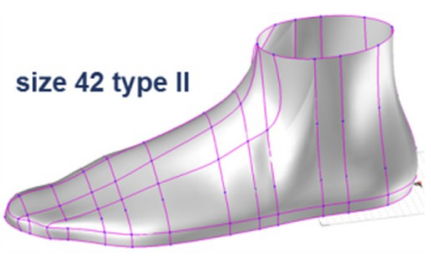

Fig. 4: Parametric models in sizes 36 to 42 and types I, II, III

The automatically generated spline surfaces of feet can be evaluated in terms of shape accuracy based on polygon models of middle feet. The false-color display presented Figure 5 highlights the differences between medium-height polygon models and computed spline surfaces. The shape congruence of such complex geometries is considered to be very positive. 


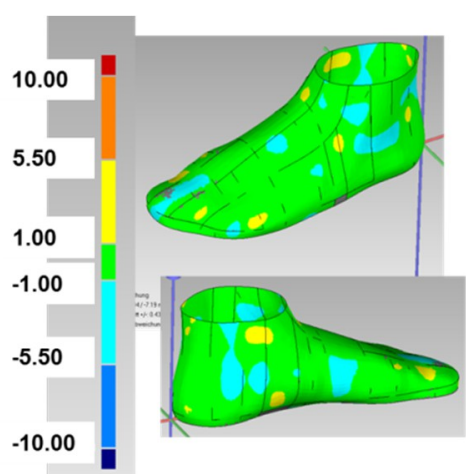

size 36, type II

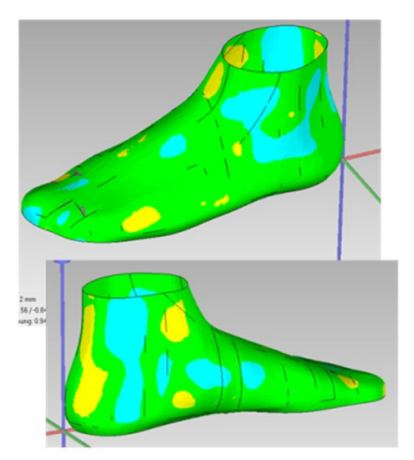

size 39, type II

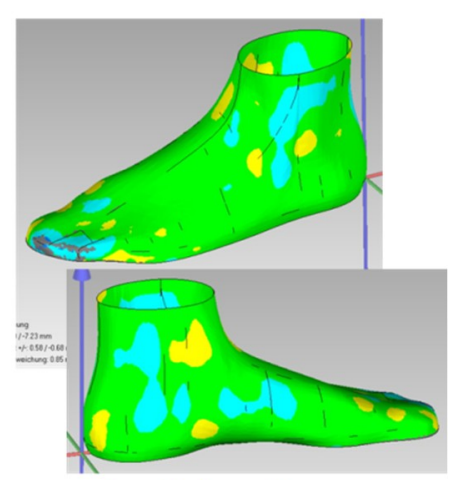

size 42, type II

Fig. 5: Investigation on shape accuracy based on polygon model and spline surfaces

\section{Grading of virtual 3D lasts}

Virtual 3D lasts are created based on parametric foot models, whereby 3D grading is automatically transferred to the lasts. In principle, all generated lasts include a variable heel height.

Since scanning with defined heel height poses a challenging task (shading during the scanning process), simulations are to reveal the changes in feet due to heel height. Thus, a geometry of the model foot (Fig. 6) is generated with a heel height of $10 \mathrm{~mm}$. In addition to changes in height, changes in width must also be addressed in this context. Therefore, the foot is subdivided into a combination of several parts in order to simplify its structure. Anatomical factors (joints, freedom of movements) are considered as well. In accordance with measurement data provided by the Test and Research Institute Pirmasens, the shape of the foot can be adjusted by modifying height, scaling, and shifting.

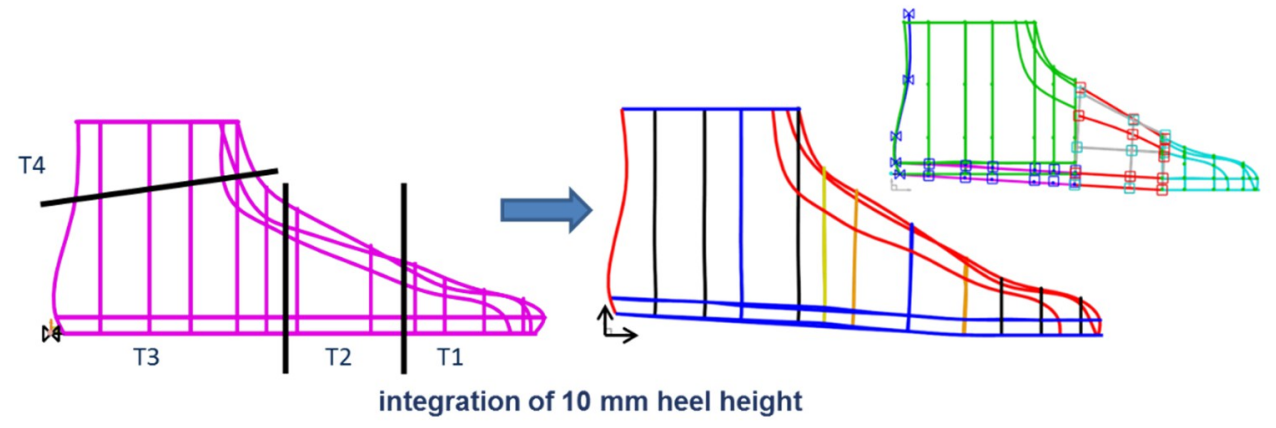

Fig. 6: Splitting of foot and integration of heel heights

An additional process step consists in the integration of heel heights into the parameterization of foot models and the determination of foot-last differences between dimensions relevant to the construction process and 3D point coordinates. Digital lasts are then converted into spline surfaces, positioned in the coordinate system, and measured by means of established design-relevant relationships. Due to the strongly bent shape of the last, it was thoroughly investigated which amount of boundary curves and patches are required to ensure the precise resemblance of last geometry (Fig. 7).

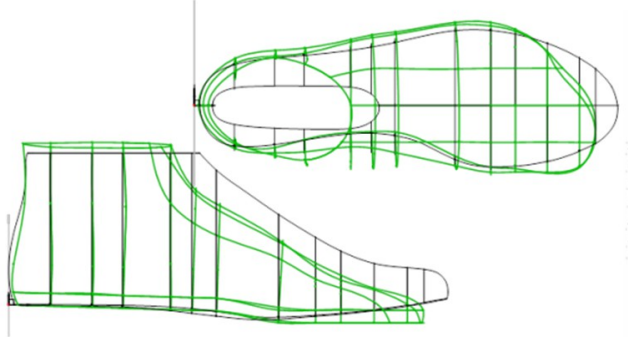

Distances between foot and shoe last in respective levels

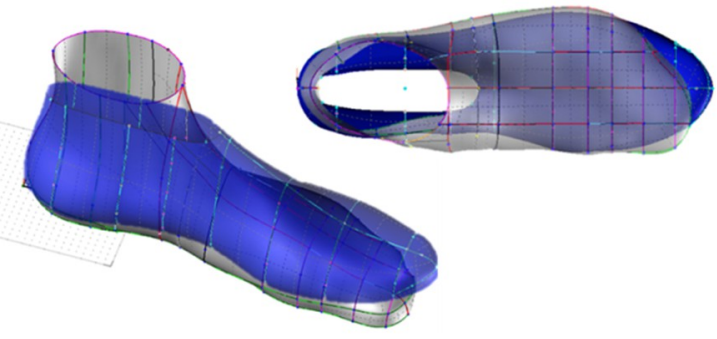

Generation of the shoe lasts based on the 3D foot models

Fig. 7: Virtual 3D shoe last with $10 \mathrm{~mm}$ heel height based on parametric $3 D$ foot model 
These determined distances und directions are an integral part of the construction design; thus, lasts are automatically modified according to the foot size or shape data stored in Excel sheets once foot dimensions or another size are selected. Satisfactory grading results for lasts are currently achieved by distance parameters that change depending on different sizes. Presently, this method also involves an enormous amount of time and effort.

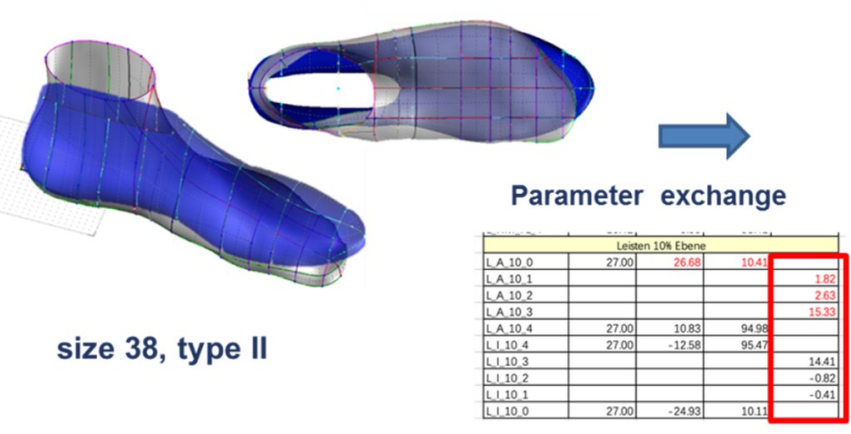

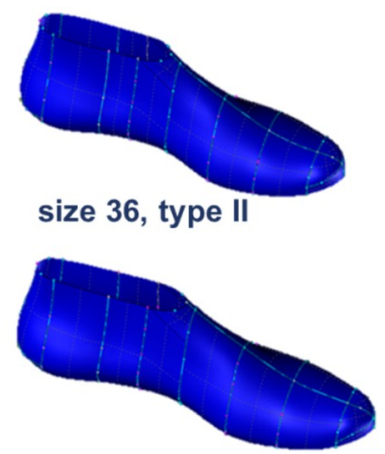

size 42, type II

Fig. 8: Grading of 3D shoe last with distance parameters changing according to size

In terms of fit, it was shown that identical distance parameters for all sizes do not yield favorable last shapes. Since feet anthropometry/shapes vary according to different sizes, the use of identical distance parameters is an unsuitable approach. Hence, in order to improve this issue, the geometry of middle feet must be further enhanced to establish a good compromise between customization and industrial manufacturing processes.

\section{Conclusion}

Previously, the construction and grading of shoe lasts had been performed based on empirical experience and outdated grading techniques due to a lack of knowledge on foot/last correlation. This deficit can be resolved by direct construction/grading based on a virtual middle foot, thus rationalizing product development. However, this innovative grading technique requires fundamental changes to the grading methods currently used in the shoe manufacturing sector.

Research is the foundation for the development of an effective new technology for the construction and $3 \mathrm{D}$ grading of shoe lasts. Based on results generated within the presented research project, lasts can be modified according to varying types of foot width. In conclusion, customer satisfaction and purchase frequency are increased, leading to a growing market success within this sector. Since product development is a particularly cost-intensive process, the targeted use of state-of-the-art technology aims at reducing required working times.

\section{Acknowledgment}

The IGF research project 18838 BG of the "Prüf- und Forschungsinstitut Pirmasens e.V." is funded through the AiF within the program for supporting the "Industrielle Gemeinschaftsforschung (IGF)" from funds of the Federal Ministry for Economic Affairs and Energy by a resolution of the German Bundestag.

\section{References}

[1] Brüder Winkle: Kopierdrehbank für Schuhleisten u. dgl., DE570527A26, Jan., 1931

[2] Fagus-Werk Benscheidt, K.: Kopiermaschine für Schuhleisten und andere unregelmäßige Gegenstände, DE51372720, Nov., 1930

[3] Fagus Grecon Greten, Maß-Tabelle 112

[4] Fagus Grecon Greten, Maß-Tabelle M.A.54

[5] PFI Pirmasens e.V., TIB Dr. Richter gGmbH, Bekleidungsphysiologisches Institut Hohenstein e.V.: Entwicklung innovativer Gradierverfahren für die Schu- und Strumpfwarenindustrie. Abschlussbericht zum AiF-Forschungsvorhaben 14993 BG, Pirmasens, Thalheim, Bönigheim, Jul., 2009

[6] Prüf- und Forschungsinstitut Pirmasens e.V.: Entwicklung eines innovativen Auswahlverfahrens für passende Schuhe. Schlussbericht des IGF-Vorhabens 15857, Pirmasens, Feb., 2011 
[7] Newlast Group: EasyLast 3D CAD/CAM V 2.6 User's Guide

[8] Newlast Group: www.newlast.com/en

[9] Shafir, A.: Method and apparatus for making shoe last and/or shoe components. EP031192519, Apr., 1989

[10] Shafir, A.: Method and apparatus for making shoe last and/or shoe components. US488430905, Dez., 1989

[11] Lee, J.: Three dimension computer model full size grading system for prozessing a shoe model by a triangular geometry mode. US 6473 66729-Oct-2002

[12] Cremaschi, A.; Gemme, G.: Method for developing a series of shoe lasts distributet on a series of sizes starting from a base last. EP 135452922-Oct-2003.

[13] Cremaschi, A.; Merigo, F.: Method for grading a series of shoe lasts distributed on a series of sizes starting from a base last and shoe last so obtained. CA 248214330-Oct-2003.

[14] Lee, R. T.; Cheng, W. S.: A Multizone Scaling Method for CAD in Shoe Sole Design. Int. J. Adv. Manuf. Technol., no. vol. 19 issue 5, pp. $313-317$, Mar. 2002

[15] Кузьмичев В.; Сурикова Г. И.; Сурикова О. В.; Гниденко А. В.: Проектирование изделий легкой промышленности в САПР (САПР одежды). ISBN: 978-5-8199-0546-3, Verlag ИД ФОРУМ, 2013

[16] Petrak, S.; Rogale, D.: Systematic representation and application of a 3D computer-aided garment construction method, Part I: 3D garment basic cut construction on a virtual body model, Department of Clothing Technology, Faculty of Textile Technology, University of Zagreb, Zagreb, Croatia, 2006.

[17] Hlaing, E. C.; Krzywinski, S.; Rödel, H.: Development of 3D Virtual Models and 3D Construction Methods for Garments. 2nd International Conference on 3D Body Scanning Technologies, S. 43-51, Lugano, Schweiz, October, 2011

[18] Krzywinski, S.; Hlaing, E. C.; Rödel, H.: 3D-Hosenkonstruktion auf Basis virtueller, skalierbarer Figurinen für Frauen. Textile Network, 1-2, 2013, S. 27-28.

[19] http://assol.org/, 07.09.2018

[20] Wang, J.; Lu, G.; Li, W.; Chen, L.; Sakaguti, Y.: Interactive 3D garment design with constrained contour curves and style curves. Computer-Aided Design, 2009, Volume 41, Issue 9, p. 614-625.

[21] http://www.tpc-intl.com/index.asp, 07.09.2018

[22] Liu, Zhang, Yuen: A survey on CAD methods in 3D garment design. Computers in Industry 61 (2010) 576-593

[23] Choi, Y.I.: Size Specification for Customized Production Size and 3D Avatar: An Apparel Industry Case Study Fashion \& Text. Res. J., Vol. 17, No. 2, pp.278-286, 2015

[24] Krzywinski, S., Siegmund, J., Wendt, E.: 3D Product Development for loose Fitting Garments Based on Parametric Human Models, Proceedings. 6th International Conference on 3D Body Scanning Technologies, Lugano (Schweiz), 27.-28. Oktober 2015, DOI: 10.15221/15.010, http://dx.doi.org/10.15221/15.010

[25] Kim, Park: Basic garment pattern generation using geometric modelling method. International Journal of Clothing Science and Technology, 2007

[26] Kakinuma, Tsutsumi, Kondo, Mitani, Miyahara, Suzuki, Lida.: Customized Garment Design Supporting System for Aged People Using Digital Dress Form Model. Proceedings 13th International Conference on Geometry and Graphics, Dresden, 2008

[27] Huang, H.Q.; Mok, P.Y.; Kwok, Y.L.; Au, J.S.: Block pattern generation: From parameterizing human bodies to fit feature-aligned and flattenable 3D garments. Computers in Industry, Volume 63, Issue 7, 09/2012, p. 680-691 